\title{
Existence of solutions for integral boundary value problems of mixed fractional differential equations under resonance
}

Shiying Song ${ }^{1}$ and Yujun Cui ${ }^{*}$ (D)

\section{"Correspondence:}

cyj720201@163.com

${ }^{2}$ State Key Laboratory of Mining Disaster Prevention and Control Co-founded by Shandong Province, and the Ministry of Science and Technology, Shandong University of Science and Technology, Qingdao, P.R. China

Full list of author information is available at the end of the article

\section{Springer}

\begin{abstract}
In this paper, we concerned the existence of solutions of the following nonlinear mixed fractional differential equation with the integral boundary value problem:

$$
\left\{\begin{array}{l}
{ }^{C} D_{1-}^{\alpha} D_{0+}^{\beta} u(t)=f\left(t, u(t), D_{0+}^{\beta+1} u(t), D_{0+}^{\beta} u(t)\right), \quad 0<t<1, \\
u(0)=u^{\prime}(0)=0, \quad u(1)=\int_{0}^{1} u(t) d A(t),
\end{array}\right.
$$

where ${ }^{C} D_{1-}^{\alpha}$ is the left Caputo fractional derivative of order $\alpha \in(1,2]$, and $D_{0+}^{\beta}$ is the right Riemann-Liouville fractional derivative of order $\beta \in(0,1]$. The coincidence degree theory is the main theoretical basis to prove the existence of solutions of such problems.
\end{abstract}

MSC: Primary 34A34; secondary 34B18; 46B45

Keywords: Left Caputo fractional derivative; Right Riemann-Liouville fractional derivative; Boundary value problem; Resonance; Coincidence degree theory

\section{Introduction}

In this paper, we study the following integral boundary value problems of the mixed fractional differential equations under resonance:

$$
\left\{\begin{array}{l}
{ }^{C} D_{1-}^{\alpha} D_{0+}^{\beta} u(t)=f\left(t, u(t), D_{0+}^{\beta+1} u(t), D_{0+}^{\beta} u(t)\right), \quad 0<t<1, \\
u(0)=u^{\prime}(0)=0, \quad u(1)=\int_{0}^{1} u(t) d A(t),
\end{array}\right.
$$

where ${ }^{C} D_{1-}^{\alpha}$ and $D_{0+}^{\beta}$ are the left Caputo fractional derivative of order $\alpha \in(1,2]$ and the right Riemann-Liouville fractional derivative of order $\beta \in(0,1]$, respectively, $f \in$ $C\left([0,1] \times \mathbb{R}^{3}, \mathbb{R}\right), A(t)$ is a bounded-variation function, $\int_{0}^{1} x(t) d A(t)$ is the RiemannStieltjes integral of $x$ with respect to $A$. From the Lemma 2.3 we know that problem (1.1) is resonance if $\int_{0}^{1} t^{\beta+1} d A(t)=1$.

Due to the existence of solutions for boundary value problems of fractional differential equations widely used in applied science and technological science [1-5], they have

(c) The Author(s) 2020. This article is licensed under a Creative Commons Attribution 4.0 International License, which permits use, sharing, adaptation, distribution and reproduction in any medium or format, as long as you give appropriate credit to the original author(s) and the source, provide a link to the Creative Commons licence, and indicate if changes were made. The images or other third party material in this article are included in the article's Creative Commons licence, unless indicated otherwise in a credit line to the material. If material is not included in the article's Creative Commons licence and your intended use is not permitted by statutory regulation or exceeds the permitted use, you will need to obtain permission directly from the copyright holder. To view a copy of this licence, visit http://creativecommons.org/licenses/by/4.0/. 
become a popular research field. At present, many researchers study the existence of solutions of fractional differential equations such as the Riemann-Liouville fractional derivative problem at nonresonance [6-16], the Riemann-Liouville fractional derivative problem at resonance [17-23], the Caputo fractional boundary value problem [6, 24, 25], the Hadamard fractional boundary value problem [26-28], conformable fractional boundary value problems [29-32], impulsive problems [33-35], boundary value problems [8, 3643], and variational structure problems [44, 45].

For example, Tang et al. [24] investigated the existence of solutions for the four-point boundary value problems of fractional differential equations

$$
\left\{\begin{array}{l}
D_{0+}^{\alpha} u(t)=f\left(t, u(t), u^{\prime}(t)\right), \quad 0 \leq t \leq 1, \\
u^{\prime}(0)-\beta u(\xi)=0, \quad u^{\prime}(1)+\gamma u(\eta)=0,
\end{array}\right.
$$

where $D_{0+}^{\alpha}$ denotes the Caputo fractional derivative with $1<\alpha \leq 2$.

Zou and He [23] investigated the integral boundary value problem for resonant fractional differential equation

$$
\left\{\begin{array}{l}
-D_{0+}^{p} x(t)=f\left(t, x(t), D_{0+}^{p-1} x(t), D_{0+}^{p-2} x(t)\right), \quad 0<t<1, \\
x(0)=x^{\prime}(0)=0, \\
x(1)=\int_{0}^{1} x(t) d A(t), \quad 2<p<3
\end{array}\right.
$$

where $D_{0+}^{p}$ is the standard Riemann-Liouville differentiation. Using Mawhin's coincidence degree theory, they proved the existence of solutions.

In recent paper [9], the existence and uniqueness results for integral boundary value problem of two-term fractional differential equations

$$
\left\{\begin{array}{l}
D^{\delta} x(t)+f(t, x(t))=D^{\tau} g(t, x(t)), \quad t \in(0,1), \\
x(0)=0, \quad x(1)=\frac{1}{\Gamma(\delta-\tau)} \int_{0}^{1}(1-s)^{\delta-\tau-1} g(s, x(s)) d s
\end{array}\right.
$$

were considered by the Schauder fixed point theorem and the Banach contraction mapping principle.

Among several types of fractional differential equations found in the literature, the $\mathrm{Ca}$ puto and Riemann-Liouville derivatives are studied separately in many cases. However, the study of resonant boundary value problems involving mixed fractional-order derivatives have not been extensively studied (see $[26,46]$ ). Motivated by the literature mentioned, we consider the existence of solutions for the resonant integral boundary value problem (1.1) involving the left Caputo and right Riemann-Liouville fractional derivatives by using the Mawhin's coincidence degree theory.

In this paper, we always suppose that the following condition is satisfied:

(H1) $\int_{0}^{1} t^{\beta+1} d A(t)=1, \int_{0}^{1} t^{\beta} d A(t)-1 \neq 0$.

\section{Preliminaries}

In this paper, we first need the following necessary basic definitions. 
Definition 2.1 ([2]) The left and right Riemann-Liouville fractional integrals of order $\alpha>0$ of a function $g:(0, \infty) \rightarrow R$ are respectively given by

$$
I_{0+}^{\alpha} g(t)=\int_{0}^{t} \frac{(t-s)^{\alpha-1}}{\Gamma(\alpha)} g(s) d s
$$

and

$$
I_{1-}^{\alpha} g(t)=\int_{t}^{1} \frac{(s-t)^{\alpha-1}}{\Gamma(\alpha)} g(s) d s
$$

where the right-hand sides are pointwise defined on $(0, \infty)$, and $\Gamma$ is the gamma function.

Definition 2.2 ([2]) The left Riemann-Liouville fractional derivative and the right Caputo fractional derivative of order $\alpha>0$ of a function $g \in C^{n}((0, \infty), R)$ are given by

$$
D_{0+}^{\alpha} g(t)=\frac{d^{n}}{d t^{n}}\left(I_{0+}^{n-\alpha} g\right)(t)
$$

and

$$
{ }^{C} D_{1-}^{\alpha} g(t)=(-1)^{n} I_{1-}^{n-\alpha} g^{(n)}(t), \quad n-1<\alpha<n,
$$

respectively.

Lemma 2.1 Let $\alpha \in(1,2]$ and $\beta \in(0,1]$. For $y \in C[0,1]$, the fractional differential equation

$$
{ }^{C} D_{1-}^{\alpha} D_{0+}^{\beta} u(t)=y(t)
$$

has the general solution

$$
u(t)=I_{0+}^{\beta} I_{1-}^{\alpha} y(t)+c_{0} \frac{t^{\beta}}{\Gamma(\beta+1)}+c_{1} \frac{t^{\beta+1}}{\Gamma(\beta+2)}+c_{2} t^{\beta-1} .
$$

Proof Applying the right fractional integral $I_{1-}^{\alpha}$ to (2.1) and using the properties of Caputo fractional derivatives, we can obtain that

$$
D_{0+}^{\beta} u(t)=I_{1-}^{\alpha} y(t)+c_{0}+c_{1} t, \quad c_{0}, c_{1} \in \mathbb{R} .
$$

Applying the left fractional integral $I_{0+}^{\beta}$ to this equation and using the properties of Riemann-Liouville fractional derivatives, we have

$$
\begin{aligned}
u(t) & =I_{0+}^{\beta} I_{1-}^{\alpha} y(t)+I_{0+}^{\beta}\left(c_{0}+c_{1} t\right)+c_{2} t^{\beta-1} \\
& =I_{0+}^{\beta} I_{1-}^{\alpha} y(t)+c_{0} \frac{t^{\beta}}{\Gamma(\beta+1)}+c_{1} \frac{t^{\beta+1}}{\Gamma(\beta+2)}+c_{2} t^{\beta-1}, \quad c_{2} \in \mathbb{R} .
\end{aligned}
$$

Lemma 2.2 Let $\alpha \in(1,2]$ and $\beta \in(0,1]$. If $y \in C[0,1]$, then $u$ is a solution of the fractional differential equation

$$
\left\{\begin{array}{l}
{ }^{C} D_{1-}^{\alpha} D_{0+}^{\beta} u(t)=y(t), \quad 0<t<1 \\
u(0)=u^{\prime}(0)=u(1)=0
\end{array}\right.
$$


if and only if

$$
u(t)=I_{0+}^{\beta} I_{1-}^{\alpha} y(t)-t^{\beta+1} I_{0+}^{\beta} I_{1-}^{\alpha} y(1), \quad t \in[0,1] .
$$

Proof Conditions $u(0)=u^{\prime}(0)=0$ in (2.2) yield $c_{0}=c_{2}=0$. Consequently, (2.2) reduces to

$$
u(t)=I_{0+}^{\beta} I_{1-}^{\alpha} y(t)+c_{1} \frac{t^{\beta+1}}{\Gamma(\beta+2)}, \quad t \in[0,1] .
$$

By the boundary condition $u(1)=0$ we have

$$
c_{1}=-\Gamma(\beta+2) I_{0+}^{\beta} I_{1-}^{\alpha} y(1) .
$$

Therefore

$$
u(t)=I_{0+}^{\beta} I_{1-}^{\alpha} y(t)-t^{\beta+1} I_{0+}^{\beta} I_{1-}^{\alpha} y(1), \quad t \in[0,1] .
$$

This process is reversible.

Let $L: \operatorname{Dom} L \subset X \rightarrow Y$ be a Fredholm operator of index zero, where $X$ and $Y$ are two real Banach spaces, and let $N: X \rightarrow Y$ be a nonlinear continuous map. If $P: X \rightarrow X$ and $Q$ : $Y \rightarrow Y$ are continuous projectors such that $\operatorname{Im} P=\operatorname{Ker} L, \operatorname{Ker} Q=\operatorname{Im} L, X=\operatorname{Ker} L \oplus \operatorname{Ker} P$, and $Y=\operatorname{Im} L \oplus \operatorname{Im} Q$, then $L_{P}=\left.L\right|_{\operatorname{Dom} L \cap \operatorname{Ker} P}: \operatorname{Dom} L \cap \operatorname{Ker} P \rightarrow \operatorname{Im} L$ is invertible. By $K_{P}$ we denote the inverse of the operator $L_{P}$.

Let $\Omega$ is an open bounded subset of $X$ with $\operatorname{Dom} L \cap \Omega \neq \varnothing$. If $Q N(\bar{\Omega})$ is bounded and $K_{P}(I-Q) N: \bar{\Omega} \rightarrow X$ is compact, then we call the mapping $N: X \rightarrow Y L$-compact on $\bar{\Omega}$.

Theorem 2.1 ([47]) Let $L$ be a Fredholm operator of index zero, and let $N$ be L-compact on $\bar{\Omega}$. Assume that the following conditions are satisfied:

(i) $L u \neq \lambda N u$ for every $(u, \lambda) \in[(\operatorname{dom} L \backslash \operatorname{Ker} L) \cap \partial \Omega] \times(0,1)$;

(ii) $N u \notin \operatorname{Im} L$ for every $u \in \operatorname{Ker} L \cap \partial \Omega$;

(iii) $\operatorname{deg}\left(\left.J Q N\right|_{\operatorname{Ker} L}, \Omega \cap \operatorname{Ker} L, 0\right) \neq 0$, where $J: \operatorname{Im} Q \rightarrow \operatorname{Ker} L$ is an isomorphism.

Then the equation $L u=N u$ has at least one solution in $\operatorname{dom} L \cap \bar{\Omega}$.

We use the classical Banach space $Y=C[0,1]$ with the norm $\|u\|_{\infty}=\max _{t \in[0,1]}|u(t)|$ and the Banach space $X=\left\{u:[0,1] \rightarrow \mathbb{R} \mid u, D_{0+}^{\beta+1} u, D_{0+}^{\beta} u \in C[0,1]\right\}$ with the norm $\|x\|_{X}=$ $\max \left\{\|u\|_{\infty},\left\|D_{0+}^{\beta+1} u\right\|_{\infty},\left\|D_{0+}^{\beta} u\right\|_{\infty}\right\}$ (see [22, 23]).

After further discussion for problems (1.1), we define two operators $L$ and $N$ as follows:

$$
\begin{aligned}
& (L u)(t)={ }^{C} D_{1-}^{\alpha} D_{0+}^{\beta} u(t), \quad u \in \operatorname{Dom} L, \\
& (N u)(t)=f\left(t, u(t), D_{0+}^{\beta+1} u(t), D_{0+}^{\beta} u(t)\right), \quad u \in X,
\end{aligned}
$$

where

$$
\operatorname{Dom} L=\left\{u \in X \mid{ }^{C} D_{1-}^{\alpha} D_{0+}^{\beta} u \in Y, u(0)=u^{\prime}(0)=0, u(1)=\int_{0}^{1} u(t) d A(t)\right\},
$$

then we can write problem (1.1) as $L x=N x$. 
Next, the following lemmas play an important role in proving the existence of solutions to $(1.1)$.

Lemma 2.3 Let L be defined as in (2.3). Then

$$
\begin{aligned}
& \operatorname{ker} L=\left\{u \in X \mid u(t)=c t^{\beta+1}, c \in \mathbb{R}, t \in[0,1]\right\} \\
& \operatorname{Im} L=\left\{y \in Y\left|\int_{0}^{1} I_{0+}^{\beta} I_{1-}^{\alpha} y(t) d A(t)-I_{0+}^{\beta} I_{1-}^{\alpha} y(t)\right|_{t=1}=0\right\} .
\end{aligned}
$$

Proof By Lemma $2.1{ }^{C} D_{1-}^{\alpha} D_{0+}^{\beta} u(t)=0$ has the solution

$$
u(t)=c_{0} \frac{t^{\beta}}{\Gamma(\beta+1)}+c_{1} \frac{t^{\beta+1}}{\Gamma(\beta+2)}+c_{2} t^{\beta-1}
$$

By the boundary value condition $u(0)=u^{\prime}(0)=0$ we can infer that $c_{0}=c_{2}=0$. Consequently, (2.6) reduces to

$$
u(t)=c_{1} \frac{t^{\beta+1}}{\Gamma(\beta+2)} .
$$

Then, combining with the boundary value condition $u(1)=\int_{0}^{1} u(t) d A(t)$, we have that (2.4) holds.

If $y \in \operatorname{Im} L$, then there exists $u \in \operatorname{dom} L$ such that $y(t)={ }^{C} D_{1-}^{\alpha} D_{0+}^{\beta} u(t)$. It follows from Lemma 2.1 and the boundary value condition $u(0)=u^{\prime}(0)=0$ that

$$
u(t)=I_{0+}^{\beta} I_{1-}^{\alpha} y(t)+c_{1} \frac{t^{\beta+1}}{\Gamma(\beta+2)} .
$$

Thus we have

$$
u(1)=\left.I_{0+}^{\beta} I_{1-}^{\alpha} y(t)\right|_{t=1}+c_{1} \frac{1}{\Gamma(\beta+2)}
$$

and

$$
\begin{aligned}
\int_{0}^{1} u(t) d A(t) & =\int_{0}^{1} I_{0+}^{\beta} I_{1-}^{\alpha} y(t) d A(t)+c_{1} \frac{\int_{0}^{1} t^{\beta+1} d A(t)}{\Gamma(\beta+2)} \\
& =\int_{0}^{1} I_{0+}^{\beta} I_{1-}^{\alpha} y(t) d A(t)+c_{1} \frac{1}{\Gamma(\beta+2)} .
\end{aligned}
$$

Using the condition $u(1)=\int_{0}^{1} u(t) d A(t)$, we obtain that

$$
\int_{0}^{1} I_{0+}^{\beta} I_{1-}^{\alpha} y(t) d A(t)-\left.I_{0+}^{\beta} I_{1-}^{\alpha} y(t)\right|_{t=1}=0,
$$

so that $\operatorname{Im} L \subset\left\{y \in Y\left|\int_{0}^{1} I_{0+}^{\beta} I_{1-}^{\alpha} y(t) d A(t)-I_{0+}^{\beta} I_{1-}^{\alpha} y(t)\right|_{t=1}=0\right\}$.

On the other hand, suppose $y \in Y$ satisfies

$$
\int_{0}^{1} I_{0+}^{\beta} I_{1-}^{\alpha} y(t) d A(t)-\left.I_{0+}^{\beta} I_{1-}^{\alpha} y(t)\right|_{t=1}=0 .
$$


Let

$$
u(t)=I_{0+}^{\beta} I_{1-}^{\alpha} y(t)+t^{\beta+1} .
$$

Then ${ }^{C} D_{1-}^{\alpha} D_{0+}^{\beta} u(t)=y(t), u(0)=u^{\prime}(0)=0$, and $u(1)=\int_{0}^{1} u(t) d A(t)$. So we obtain that $y \in$ $\operatorname{Im} L$.

Thus the proof of

$$
\operatorname{Im} L=\left\{y \in Y\left|\int_{0}^{1} I_{0+}^{\beta} I_{1-}^{\alpha} y(t) d A(t)-I_{0+}^{\beta} I_{1-}^{\alpha} y(t)\right|_{t=1}=0\right\}
$$

is completed.

Lemma 2.4 Assume that $\left(H_{1}\right)$ is satisfied. Then the operator $L$ is a Fredholm operator with index zero, and two linear continuous projectors $P: X \rightarrow X$ and $Q: Y \rightarrow Y$ are respectively defined by

$$
\begin{aligned}
& (P u)(t)=u(1) t^{\beta+1}, \quad u \in X, \\
& Q y=\frac{1}{\theta\left(\int_{0}^{1} d A(t)-1\right)}\left(\int_{0}^{1} I_{0+}^{\beta} I_{1-}^{\alpha} y(t) d A(t)-I_{0+}^{\beta} I_{1-}^{\alpha} y(1)\right), \quad y \in Y,
\end{aligned}
$$

where $\theta=I_{0+}^{\beta} I_{1-}^{\alpha} 1=\frac{1}{(\alpha+\beta) \Gamma(\alpha+1) \Gamma(\beta)}$. Furthermore, let $K_{P}: \operatorname{Im} L \rightarrow \operatorname{Dom} L \cap \operatorname{Ker} P$ be a linear operator defined by

$$
\begin{aligned}
K_{P} y(t)= & I_{0+}^{\beta} I_{1-}^{\alpha} y(t)-t^{\beta+1} I_{0+}^{\beta} I_{1-}^{\alpha} y(1) \\
= & \int_{0}^{t} \frac{(t-s)^{\beta-1}}{\Gamma(\beta)} \int_{s}^{1} \frac{(\tau-s)^{\alpha-1}}{\Gamma(\alpha)} y(\tau) d \tau d s \\
& -t^{\beta+1} \int_{0}^{1} \frac{(1-s)^{\beta-1}}{\Gamma(\beta)} \int_{s}^{1} \frac{(\tau-s)^{\alpha-1}}{\Gamma(\alpha)} y(\tau) d \tau d s .
\end{aligned}
$$

Then $K_{P}$ is the inverse of $L_{P}=\left.L\right|_{\operatorname{Dom} L \cap \operatorname{Ker} P}$.

Proof For $u \in X$, we have

$$
\left(P^{2} u\right)(t)=P(P u)(t)=\left.t^{\beta+1}\left[t^{\beta+1} u(1)\right]\right|_{t=1}=(P u)(t) .
$$

So $P: X \rightarrow X$ is a linear continuous projector operator with $\operatorname{Ker} P=\operatorname{Im} L$.

Since $u=u-P u+P u$, it is easy to see that $u-P u \in \operatorname{Ker} P$ and $P u \in \operatorname{Ker} L$. Thus $X=\operatorname{Ker} P+$ $\operatorname{Ker} L$. If $u \in \operatorname{Ker} P \cap \operatorname{Ker} L$ and so $u(t)=c t^{\beta+1}$, then we can conclude that $(P u)(t)=c t^{\beta+1}=0$, and so $c=0$. Then

$$
X=\operatorname{Ker} P \oplus \operatorname{Ker} L .
$$

Take $z(t) \equiv 1$ for $t \in[0,1]$. For $y \in Y$, we have

$$
Q^{2} y(t)=\frac{Q y(t)}{\theta\left(\int_{0}^{1} d A(t)-1\right)}\left(\int_{0}^{1} I_{0+}^{\beta} I_{1-}^{\alpha} z(t) d A(t)-I_{0+}^{\beta} I_{1-}^{\alpha} z(1)\right)=Q y(t),
$$

which implies that $Q^{2}=Q$ and $\operatorname{Ker} Q=\operatorname{Im} L$. 
For $y \in Y, y=y-Q y+Q y$, we have $Y=\operatorname{Im} L+\operatorname{Im} Q$. Moreover, by direct computation we get $\operatorname{Im} L \cap \operatorname{Im} Q=\{0\}$. Thus $Y=\operatorname{Im} L \oplus \operatorname{Im} Q$. Therefore

$\operatorname{dim} \operatorname{Ker} L=\operatorname{dim} \operatorname{Im} Q=\operatorname{codim} \operatorname{Im} L=1$.

This shows that $L$ is a Fredholm operator of index zero.

Next, we will prove that $K_{P}: \operatorname{Im} L \rightarrow \operatorname{Dom} L \cap \operatorname{Ker} P$ is the inverse of $L_{P}=\left.L\right|_{\operatorname{Dom} L \cap \operatorname{Ker} P \text {. }}$ In fact, for $y \in \operatorname{Im} L$, we have

$$
L_{P} K_{P} y={ }^{C} D_{1-}^{\alpha} D_{0+}^{\beta} I_{0+}^{\beta} I_{1-}^{\alpha} y=y
$$

and for $u \in \operatorname{dom} L \cap \operatorname{ker} P$, we know that there exists $y \in Y$ such that

$$
\left\{\begin{array}{l}
{ }^{C} D_{1-}^{\alpha} D_{0+}^{\beta} u(t)=y(t), \quad 0<t<1 \\
u(0)=u^{\prime}(0)=u(1)=0
\end{array}\right.
$$

In view of Lemma 2.2, we get

$$
\left(K_{p} L\right) u(t)=\left(K_{p} y\right)(t)=u(t)
$$

which shows that $K_{P}=\left(\left.L\right|_{\operatorname{dom} L \cap \operatorname{ker} P}\right)^{-1}$.

Thus the proof that $K_{P}$ is the inverse of $L_{P}=\left.L\right|_{\operatorname{Dom} L \cap \operatorname{Ker} P}$ is complete.

By standard arguments we have the following lemma.

Lemma 2.5 $K_{P}(I-Q) N: Y \rightarrow Y$ is completely continuous.

Lemma 2.6 For $y \in Y$, let

$$
(T y)(t)=I_{0+}^{\beta} I_{1-}^{\alpha} y(t)=\int_{0}^{t} \frac{(t-s)^{\beta-1}}{\Gamma(\beta)} \int_{s}^{1} \frac{(\tau-s)^{\alpha-1}}{\Gamma(\alpha)} y(\tau) d \tau d s
$$

Then

$$
\begin{aligned}
& \|T y\|_{\infty} \leq \frac{1}{\Gamma(\beta+1) \Gamma(\alpha+1)}\|y\|_{\infty} \\
& \left\|D_{0+}^{\beta}(T y)\right\|_{\infty} \leq \frac{1}{\Gamma(\alpha+1)}\|y\|_{\infty}, \\
& \left\|D_{0+}^{\beta+1}(T y)\right\|_{\infty} \leq \frac{1}{\Gamma(\alpha)}\|y\|_{\infty} .
\end{aligned}
$$

Moreover,

$$
\|T y\|_{X} \leq \Delta\|y\|_{\infty}
$$

where $\Delta=\max \left\{\frac{1}{\alpha \Gamma(\beta+1)}, 1\right\} \frac{1}{\Gamma(\alpha)}$. 
Proof Applying the left fractional derivative $D_{0+}^{\beta}$ and $D_{0_{+}}^{\beta+1}$, respectively, and using the properties of Riemann-Liouville fractional derivatives, we get

$$
D_{0+}^{\beta}(T y)(t)=I_{1-}^{\alpha} y(t)=\int_{t}^{1} \frac{(s-t)^{\alpha-1}}{\Gamma(\alpha)} y(s) d s
$$

and

$$
D_{0+}^{\beta+1}(T y)(t)=-\int_{t}^{1} \frac{(s-t)^{\alpha-2}}{\Gamma(\alpha-1)} y(s) d s .
$$

Consequently,

$$
\begin{aligned}
&|(T y)(t)| \leq\left|\int_{0}^{t} \frac{(t-s)^{\beta-1}}{\Gamma(\beta)} \frac{(1-s)^{\alpha}}{\Gamma(\alpha+1)} d s\right|\|y\|_{\infty} \leq\left|\int_{0}^{t} \frac{(t-s)^{\beta-1}}{\Gamma(\beta) \Gamma(\alpha+1)} d s\right|\|y\|_{\infty} \\
&=\left|\frac{t^{\beta}}{\Gamma(\beta+1) \Gamma(\alpha+1)}\right|\|y\|_{\infty} \leq \frac{1}{\Gamma(\beta+1) \Gamma(\alpha+1)}\|y\|_{\infty}, \\
&\left|D_{0+}^{\beta}(T y)(t)\right| \leq\left|\int_{t}^{1} \frac{(s-t)^{\alpha-1}}{\Gamma(\alpha)} d s\right|\|y\|_{\infty} \leq \frac{1}{\Gamma(\alpha+1)}\|y\|_{\infty},
\end{aligned}
$$

and

$$
\left|D_{0+}^{\beta+1}(T y)(t)\right| \leq\left|\int_{t}^{1} \frac{(s-t)^{\alpha-2}}{\Gamma(\alpha-1)} d s\right|\|y\|_{\infty} \leq \frac{1}{\Gamma(\alpha)}\|y\|_{\infty},
$$

which, on taking the norm for $t \in[0,1]$, yields

$$
\|T y\|_{X}=\max \left\{\|T y\|_{\infty},\left\|D_{0_{+}}^{\beta}(T y)\right\|_{\infty},\left\|D_{0_{+}}^{\beta+1}(T y)\right\|_{\infty}\right\} \leq \Delta\|y\|_{\infty} .
$$

\section{Main results}

In this section, we use Theorem 2.1 to prove the existence of solutions to IBVP (1.1).

To get our main result, we need the following conditions:

(H2) There exists a constant $B>0$ such that either for each $c \in \mathbb{R}:|c|>B$,

$$
c Q N\left(c t^{\beta+1}\right)>0
$$

or for each $c \in \mathbb{R}:|c|>B$,

$$
c Q N\left(c t^{\beta+1}\right)<0
$$

(H3) There exist functions $\rho, \sigma, \tau, \gamma \in C[0,1]$ such that, for all $(u, v, w) \in \mathbb{R}^{3}$ and $t \in[0,1]$,

$$
|f(t, u, v, w)| \leq \rho(t)+\sigma(t)|u|+\tau(t)|v|+\gamma(t)|w|
$$

(H4) There exists a constant $M>0$ such that if $\left|D_{0+}^{\beta+1} u(t)\right|>M$ for all $t \in[0,1]$, and then $Q N u \neq 0$. 
Theorem 3.1 If (H1), (H2), (H3), (H4) hold, then IBVP (1.1) has at least one solution in $X$, provided that

$$
\|\sigma\|_{\infty}+\|\tau\|_{\infty}+\|\gamma\|_{\infty}<\frac{\Gamma(\alpha)}{\Gamma(\alpha)+\Delta} .
$$

Proof Set

$$
\Omega_{1}=\{u \in \operatorname{dom} L \backslash \operatorname{Ker} L: L u=\lambda N u \text { for some } \lambda \in[0,1]\} .
$$

For $u \in \Omega_{1}$, since $L u=\lambda N u$ and so $\lambda \neq 0, N u \in \operatorname{Im} L=\operatorname{Ker} Q$, and hence

$$
Q N u=0 .
$$

Thus, By $(H 4)$ there exists $t_{0} \in[0,1]$ such that

$$
\left|D_{0+}^{\beta+1} u\left(t_{0}\right)\right| \leq M .
$$

It follows from Lemma 2.1 and $u(0)=u^{\prime}(0)=0$ that there exists $c_{1} \in \mathbb{R}$ such that the function $u$ satisfies

$$
u(t)=\lambda I_{0+}^{\beta} I_{1-}^{\alpha} N u(t)+c_{1} \frac{t^{\beta+1}}{\Gamma(\beta+2)}=\lambda T(N u)(t)+c_{1} \frac{t^{\beta+1}}{\Gamma(\beta+2)},
$$

where the operator $T$ is defined by (2.7). Applying the left fractional derivative $D_{0_{+}}^{\beta+1}$ to this equation and using the properties of fractional derivative, we get

$$
D_{0+}^{\beta+1} u(t)=\lambda D_{0+}^{\beta+1} I_{0+}^{\beta} I_{1-}^{\alpha} N u(t)+c_{1}=-\lambda I_{1-}^{\alpha-1} N u(t)+c_{1} .
$$

Therefore

$$
\left|c_{1}\right| \leq\left|D_{0+}^{\beta+1} u\left(t_{0}\right)\right|+\left|I_{1-}^{\alpha-1} N u\left(t_{0}\right)\right| \leq M+\frac{1}{\Gamma(\alpha)}\|N u\|_{\infty} .
$$

This, together with Lemma 2.6, yields

$$
\begin{aligned}
\|u\|_{X} & =\max \left\{\|u\|_{\infty},\left\|D_{0+}^{\beta} u\right\|_{\infty},\left\|D_{0+}^{\beta+1} u\right\|_{\infty}\right\} \\
& \leq \max \left\{\|T(N u)\|_{\infty},\left\|D_{0^{\prime}}^{\beta} T(N u)\right\|_{\infty},\left\|D_{0+}^{\beta+1} T(N u)\right\|_{\infty}\right\}+\left|c_{1}\right| \\
& \leq M+\left(\frac{1}{\Gamma(\alpha)}+\Delta\right)\|N u\|_{\infty} \\
& \leq M+\left(\frac{1}{\Gamma(\alpha)}+\Delta\right)\left(\|\sigma\|_{\infty}+\|\tau\|_{\infty}+\|\gamma\|_{\infty}\right)\|u\|_{X} .
\end{aligned}
$$

Thus from (3.3) we obtain that

$$
\|u\|_{X} \leq \frac{M \Gamma(\alpha)}{\Gamma(\alpha)-(\Gamma(\alpha)+\Delta)\left(\|\sigma\|_{\infty}+\|\tau\|_{\infty}+\|\gamma\|_{\infty}\right)} .
$$

Therefore $\Omega_{1}$ is bounded. 
Now we denote $\Omega_{2}=\{u \in \operatorname{Ker} L: N u \in \operatorname{Im} L\}$. If $u \in \Omega_{2}$, then $u=c t^{\beta+1}, c \in \mathbb{R}$, and it is easy to deduce that $Q N u(t)=0$. By $(H 2)$ we obtain $|c| \leq B$. Therefore $\Omega_{2}$ is a bounded set. Now we define the isomorphism $J: \operatorname{Im} Q \rightarrow \operatorname{Ker} L$ by

$$
J(c)=c t^{\beta+1} \text {. }
$$

If (3.1) holds, then let

$$
\Omega_{3}=\{u \in \operatorname{Ker} L: \lambda u+(1-\lambda) J Q N u=0, \lambda \in[0,1]\} .
$$

For $u=c t^{\beta+1} \in \Omega_{3}$, we have

$$
\lambda c t^{\beta+1}=-(1-\lambda) t^{\beta+1} Q N\left(c t^{\beta+1}\right) .
$$

So we get

$$
\lambda c=-(1-\lambda) Q N\left(c t^{\beta+1}\right) .
$$

If $\lambda=1$, then $c=0$. Otherwise, if $|c|>B$, in view of (H2), we have

$$
c(1-\lambda) Q N\left(c t^{\beta+1}\right)>0,
$$

which contradicts $\lambda c^{2} \geq 0$. Thus $\Omega_{3}$ is bounded.

If (3.2) holds, then define the set

$$
\Omega_{3}=\{u \in \operatorname{Ker} L:-\lambda u+(1-\lambda) J Q N u=0, \lambda \in[0,1]\},
$$

where $J$ is as before. Similarly to the previous argument, we can show that $\Omega_{3}$ also is bounded.

Next, we will prove that all the assumptions of Theorem 2.1 are satisfied. Let $\Omega$ be any bounded open subset of $Y$ such that $\bigcup_{i=1}^{3} \overline{\Omega_{i}} \subset \Omega$. By Lemma $2.5 K_{P}(I-Q) N: \Omega \rightarrow Y$ is compact, and thus $N$ is $L$-compact on $\bar{\Omega}$.

Clearly, assumptions (i) and (ii) of Theorem 2.1 are fulfilled.

Finally, we will prove that (iii) of Theorem 2.1 is satisfied.

Let $F(u, \lambda)= \pm \lambda x+(1-\lambda) J Q N u$. According to previous argument, we have

$$
F(u, \lambda) \neq 0 \quad \text { for } u \in \operatorname{Ker} L \cap \partial \Omega \text {. }
$$

Thus by the homotopy property of degree we have

$$
\begin{aligned}
\operatorname{deg}\left(\left.J Q N\right|_{\operatorname{Ker} L}, \operatorname{Ker} L \cap \Omega, 0\right) & =\operatorname{deg}(F(\cdot, 0), \operatorname{Ker} L \cap \Omega, 0) \\
& =\operatorname{deg}(F(\cdot, 1), \operatorname{Ker} L \cap \Omega, 0) \\
& =\operatorname{deg}( \pm I, \operatorname{Ker} L \cap \Omega, 0) \neq 0 .
\end{aligned}
$$

Then by Theorem $2.1 L u=N u$ has at least one solution in $\operatorname{dom} L \cap \bar{\Omega}$, so that IBVP (1.1) has a solution. 


\section{Acknowledgements}

The authors thank anonymous referees for their valuable suggestions.

\section{Funding}

This work was partially supported by the National Natural Science Foundation of China $(11371221,11571207,51774197)$, the Shandong Natural Science Foundation (ZR2018MA011), SDUST graduate innovation project (SDKDYC190238), and the Tai'shan Scholar Engineering Construction Fund of Shandong Province of China.

\section{Abbreviations}

Not applicable.

\section{Availability of data and materials}

Data sharing not applicable to this paper as no data sets were generated or analyzed during the current study.

\section{Competing interests}

The authors declare that they have no competing interests.

\section{Authors' contributions}

The authors equally contributed in preparing this manuscript. Both authors read and approved the final manuscript.

\section{Author details}

'Department of Applied Mathematics, Shandong University of Science and Technology, Qingdao, P.R. China. ${ }^{2}$ State Key Laboratory of Mining Disaster Prevention and Control Co-founded by Shandong Province, and the Ministry of Science and Technology, Shandong University of Science and Technology, Qingdao, P.R. China.

\section{Publisher's Note}

Springer Nature remains neutral with regard to jurisdictional claims in published maps and institutional affiliations.

Received: 25 August 2019 Accepted: 20 January 2020 Published online: 30 January 2020

\section{References}

1. Agarwal, R.P., Benchohra, M., Hamani, S.: A survey on existence results for boundary value problems of nonlinear fractional differential equations and inclusions. Acta Appl. Math. 109, 973-1033 (2010)

2. Kilbas, A.A., Srivastava, H.M., Trujillo, J.J. Theory and Applications of Fractional Differential Equations. Elsevier, Amsterdam (2006)

3. Guo, M., Dong, H., Liu, J., Yang, H.: The time-fractional mZK equation for gravity solitary waves and solutions using sech-tanh and radial basic function method. Nonlinear Anal., Model. Control 24(1), 1-19 (2019)

4. Guo, M., Fu, Ch., Zhang, Y., Liu, J., Yang, H.: Study of ion-acoustic solitary waves in a magnetized plasma using the three-dimensional time-space fractional Schamel-KdV equation. Complexity 2018, Article ID 6852548 (2018)

5. Wang, Z., Huang, X., Shi, G.: Analysis of nonlinear dynamics and chaos in a fractional order financial system with time delay. Comput. Math. Appl. 62, 1531-1539 (2011)

6. Ahmad, B., Ntouyas, S., Alsaedi, A.: Fractional order differential systems involving right Caputo and left Riemann-Liouville fractional derivatives with nonlocal coupled conditions. Bound. Value Probl. 2019, Article ID 109 (2019)

7. Guo, L., Liu, L., Wu, Y.: Existence of positive solutions for singular fractional differential equations with infinite-point boundary conditions. Nonlinear Anal., Model. Control 21(5), 635-650 (2016)

8. Sun, Q., Ji, H., Cui, Y.: Positive solutions for boundary value problems of fractional differential equation with integral boundary conditions. J. Funct. Spaces 2018, Article ID 6461930 (2018)

9. Xu, M., Han, Zh.: Positive solutions for integral boundary value problem of two-term fractional differential equations. Bound. Value Probl. 2018, Article ID 100 (2018)

10. Yue, Zh., Zou, Y: New uniqueness results for fractional differential equation with dependence on the first order derivative. Adv. Differ. Equ. 2019, Article ID 38 (2019)

11. Zhang, L., Ahmad, B., Wang, G.: The existence of an extremal solution to a nonlinear system with the right-handed Riemann-Liouville fractional derivative. Appl. Math. Lett. 31, 1-6 (2014)

12. Zhang, X., Liu, L., Wu, Y.: Multiple positive solutions of a singular fractional differential equation with negatively perturbed term. Math. Comput. Model. 55(3-4), 1263-1274 (2012)

13. Zhang, X., Liu, L., Wu, Y., Zou, Y.: Existence and uniqueness of solutions for systems of fractional differential equations with Riemann-Stieltjes integral boundary condition. Adv. Differ. Equ. 2018, Article ID 204 (2018)

14. Zhao, Y., Sun, S., Han, Z., Li, Q.: The existence of multiple positive solutions for boundary value problems of nonlinear fractional differential equations. Commun. Nonlinear Sci. Numer. Simul. 16(4), 2086-2097 (2011)

15. Zou, Y.: Positive solutions for a fractional boundary value problem with a perturbation term. J. Funct. Spaces 2018 Article ID 9070247 (2018)

16. Zou, Y., He, G.: On the uniqueness of solutions for a class of fractional differential equations. Appl. Math. Lett. 74, 68-73 (2017)

17. Jankowski, T:: Monotone iterative method for first-order differential equations at resonance. Appl. Math. Comput. 233, 20-28 (2014)

18. Jiang, W., Kosmatov, N.: Solvability of a third-order differential equation with functional boundary conditions at resonance. Bound. Value Probl. 2017, Article ID 81 (2017)

19. Kosmatov, N., Jiang, W.: Resonant functional problems of fractional order. Chaos Solitons Fractals 91, 573-579 (2016)

20. Sun, Q., Meng, S., Cui, Y.: Existence results for fractional order differential equation with nonlocal Erdelyi-Kober and generalized Riemann-Liouville type integral boundary conditions at resonance. Adv. Differ. Equ. 2018, Article ID 24 (2018) 
21. Zhang, Y.: Existence results for a coupled system of nonlinear fractional multi-point boundary value problems at resonance. J. Inequal. Appl. 2018, Article ID 198 (2018)

22. Zhang, Sh., Hu, L., Shi, A.: Existence result for a nonlinear fractional differential equation with integral boundary conditions at resonance. Adv. Differ. Equ. 2013, Article ID 353 (2013)

23. Zou, Y., He, G.: The existence of solutions to integral boundary value problems of fractional differential equations at resonance. J. Funct. Spaces 2017, Article ID 2785937 (2017)

24. Tang, X.: Existence of solutions of four-point boundary value problems for fractional differential equations at resonance. J. Appl. Math. Comput. 51, 145-160 (2016)

25. Wang, F., Cui, Y.: Positive solutions for an infinite system of fractional order boundary value problems. Adv. Differ. Equ. 2019, Article ID 169 (2019)

26. Khaldi, R., Guezane-Lakoud, A.: Higher order fractional boundary value problems for mixed type derivatives. J. Nonlinear Funct. Anal. 2017, Article ID 30 (2017)

27. Ntouyas, S.K., Tariboon, J., Sudsutad, W.: Boundary value problems for Riemann-Liouville fractional differential inclusions with nonlocal Hadamard fractional integral conditions. Mediterr. J. Math. 13(3), 939-954 (2016)

28. Riaz, U., Zada, A., Ali, Z., Cui, Y., Xu, J.: Analysis of coupled systems of implicit impulsive fractional differential equations involving Hadamard derivatives. Adv. Differ. Equ. 2019, Article ID 226 (2019)

29. Li, H., Zhang, J.: Positive solutions for a system of fractional differential equations with two parameters. J. Funct. Spaces 2018, Article ID 1462505 (2018)

30. Meng, Sh., Cui, Y.: The extremal solution to conformable fractional differential equations involving integral boundary condition. Mathematics 7, Article ID 186 (2019)

31. Meng, Sh., Cui, Y:: Multiplicity results to a conformable fractional differential equations involving integral boundary condition. Complexity 2019, Article ID 8402347 (2019)

32. Song, Q., Dong, X., Bai, Z., Chen, B.: Existence for fractional Dirichlet boundary value problem under barrier strip conditions. J. Nonlinear Sci. Appl. 10, 3592-3598 (2017)

33. Feckan, M., Wang, J.R.: Periodic impulsive fractional differential equations. Adv. Nonlinear Anal. 8(1), 482-496 (2019)

34. Hao, X., Zuo, M., Liu, L.: Multiple positive solutions for a system of impulsive integral boundary value problems with sign-changing nonlinearities. Appl. Math. Lett. 82, 24-31 (2018)

35. Zuo, M., Hao, X., Liu, L., Cui, Y.: Existence results for impulsive fractional integro-differential equation of mixed type with constant coefficient and antiperiodic boundary conditions. Bound. Value Probl. 2017, Article ID 161 (2017)

36. Ahmad, B., Matar, M., Agarwal, R.: Existence results for fractional differential equations of arbitrary order with nonlocal integral boundary conditions. Bound. Value Probl. 2015, Article ID 220 (2015)

37. Cabada, A., Hamdi, Z:: Nonlinear fractional differential equations with integral boundary value conditions. Appl. Math. Comput. 228, 251-257 (2014)

38. Cui, Y., Zou, Y.: An existence and uniqueness theorem for a second order nonlinear system with coupled integral boundary value conditions. Appl. Math. Comput. 256, 438-444 (2015)

39. Cui, Y., Zou, Y.: Existence of solutions for second-order integral boundary value problems. Nonlinear Anal., Model. Control 21(6), 828-838 (2016)

40. Graef, J.R., Kong, L., Kong, Q., Wang, M.: Fractional boundary value problems with integral boundary conditions. Appl. Anal. 92, 2008-2020 (2013)

41. Hao, X., Zhang, L., Liu, L.: Positive solutions of higher order fractional integral boundary value problem with a parameter. Nonlinear Anal., Model. Control 24(2), 201-233 (2019)

42. Qi, T., Liu, Y., Zou, Y.: Existence result for a class of coupled fractional differential systems with integral boundary value conditions. J. Nonlinear Sci. Appl. 10(7), 4034-4045 (2017)

43. Song, Q., Bai, Z:: Positive solutions of fractional differential equations involving the Riemann-Stieltjes integral boundary condition. Adv. Differ. Equ. 2018, Article ID 183 (2018)

44. Li, D., Chen, F., An, Y.: Existence and multiplicity of nontrivial solutions for nonlinear fractional differential systems with p-Laplacian via critical point theory. Math. Methods Appl. Sci. 41(8), 3197-3212 (2018)

45. Wang, Y., Liu, Y., Cui, Y.: Infinitely many solutions for impulsive fractional boundary value problem with $p$-Laplacian. Bound. Value Probl. 2018, Article ID 94 (2018)

46. Guezane Lakoud, A., Khaldi, R., Kilicman, A.: Existence of solutions for a mixed fractional boundary value problem. Adv. Differ. Equ. 2017, Article ID 164 (2017)

47. Mawhin, J.: Topological degree and boundary value problems for nonlinear differential equations. In: Topological Methods for Ordinary Differential Equations. Lecture Notes in Mathematics, vol. 1537, pp. 74-142. Springer, Berlin (1993)

\section{Submit your manuscript to a SpringerOpen ${ }^{\circ}$ journal and benefit from:}

- Convenient online submission

- Rigorous peer review

- Open access: articles freely available online

- High visibility within the field

- Retaining the copyright to your article

Submit your next manuscript at $\gg$ springeropen.com 